\title{
Strategi Komunikasi Pemasaran PT. Han Indotama Perkasa Dalam Memperkenalkan Brand Minuman Han Dynastea
}

\author{
Meilindy Permata Sari, Yugih Setyanto \\ meilindymeilindy@yahoo.com,yugihs@fikom.untar.ac.id \\ Fakultas Ilmu Komunikasi Universitas Tarumanagara
}

\begin{abstract}
Important communication activities for companies to influence the level of sales and public awareness of the products offered. The better the communication activities in the promotion carried out, the more consumers will buy interest in the product. With the communication strategy carried out, such as through customers who publish photos of HAN Dynastea beverage products in social media, it helps in increasing the level of awareness and interest in buying products from HAN Dynastea. The purpose of this study was to determine the marketing communication strategy carried out by PT HAN INDOTAMA PERKASA in introducing the Han Dynastea beverage brand. The research method uses qualitative with case studies. Informant are the Chief Executive Officer, customer, and HAN Dynastea store employees. The results showed that Han Dynastea used the push and pull strategy in selling beverage products to introduce the Han Dynastea beverage brand. To build a good image Han Dynastea does an activity through marketing communications such as providing good service to customers, offering menus from Han Dynastea beverage product variants, and giving rewards through special members to customers. Han Dynastea also uses a distinctive and attractive logo as a sign of the brand's beverage brand to create brand awareness.
\end{abstract}

Keywords: Marketing Communication Strategy, Brand, Brand Awareness

\begin{abstract}
Abstrak
Kegiatan komunikasi penting untuk dilakukan perusahaan agar dapat mempengaruhi tingkat penjualan serta kesadaran masyarakat akan produk yang ditawarkan. Semakin baik kegiatan komunikasi dalam promosi yang dilakukan, maka semakin meningkatnya minat beli konsumen akan produk tersebut. Dengan strategi komunikasi yang dilakukan seperti melalui customer yang mempublikasi foto produk minuman HAN Dynastea dimedia sosial membantu dalam meningkatkan tingkat kesadaran serta minat beli akan produk dari HAN Dynastea. Tujuan penelitian ini adalah mengetahui strategi komunikasi pemasaran yang dilakukan oleh PT HAN INDOTAMA PERKASA dalam memperkenalkan brand minuman Han Dynastea. Metode penelitian menggunakan kualitatif dengan studi kasus. Informan adalah Chief Executive Officer, customer, dan karyawan store HAN Dynastea. Hasil penelitian menunjukkan bahwa Dalam kegiatan penjualan produk minumannya Han Dynastea menggunakan strategi push and pull dalam memperkenalkan brand minuman Han Dynastea. Untuk membangun suatu image yang baik Han Dynastea melakukan suatu kegiatan melalui komunikasi pemasaran seperti memberi pelayanan yang baik kepada customer, menawarkan menu dari varian produk minuman Han Dynastea, dan memberikan reward melalui member khusus pada pelanggan. Han Dynastea juga menggunakan logo yang khas dan menarik sebagai tanda pengenal dari merek brand minumannya untuk menciptakan brand awareness.
\end{abstract}

Kata Kunci: Strategi Komunikasi Pemasaran, Merek, Kesadaran Merek 


\section{Pendahuluan}

Komunikasi yang dilakukan setiap perusahaan tentu berbeda-beda dan memiliki keunikan tersendiri. Kegiatan komunikasi penting untuk dilakukan perusahaan agar dapat mempengaruhi tingkat penjualan serta kesadaran masyarakat akan produk yang ditawarkan. Semakin baik kegiatan komunikasi dalam promosi yang dilakukan, maka semakin meningkatnya minat beli konsumen akan produk tersebut.

Cheese Tea atau teh keju yang kian populer ini berawal dari Taiwan. Minuman dengan rasa yang unik ini tentu sudah bisa dicicip di Jakarta. Setelah milk tea, di Taiwan muncul tren paduan teh dengan keju benama Cheese Tea. Diracik dari teh panas atau dingin lalu diberi lapisan lembut krim keju di atasnya. Di Indonesia, cheese tea pertama kali saya ketahui di Jakarta yaitu Kamu Tea yang salah satu gerainya berlokasi di Mall Aeon Cakung Jakarta Timur dimana gerai cheese tea ini menyediakan aneka minuman teh dengan paduan keju. Karena memiliki lapisan krim keju di atasnya maka untuk meminum minuman ini ada panduannya. Pertama, sobek lembaran plastik di atas gelas dengan pisau plastik kecil. Agar krim keju dapat dirasakan langsung mengenai mulut. Jika menggunakan sedotan, kita bisa mencicip paduan teh dan keju secara bersamaan. Kalau suka, dapat juga mencampurkan teh dan keju. (https://m.detik.com/food/info-kuliner/d-3895304/gimana-ya-rasa-teh-melatidan-cokelat-kalau-dilapisi-cream-cheese?ga=2.35246497.1411258736.15524580421411790695.1552458042).

Salah satu perusahaan yang baru berdiri dan menciptakan sebuah brand minuman yang sedang naik daun ini adalah PT. HAN INDOTAMA PERKASA. PT. HAN INDOTAMA PERKASA membawahi anak perusahaan yaitu brand minuman HAN Dynastea dengan menciptakan inovasi baru produk minuman olahan modifikasi teh yang berdiri sejak tahun 2018 dan diproduksi di Jakarta. HAN Dynastea memilih produk minuman teh ini karena melihat banyaknya peminat konsumen yang menyukai minuman-minuman hits jaman sekarang. Ini juga karena masyarakat lebih meminati minuman dengan rasa yang unik dan kemasan menarik untuk dapat di posting di media sosial. Dengan ini perusahaan juga mendapat keuntungan promosi secara tidak langsung melalui media sosial yang kemudian produk akan lebih diketahui masyarakat.

Menurut hasil wawancara yang didapatkan dari Chief Executive Officer (CEO) HAN Dynastea bahwa konsumen lebih menyukai produk minuman dengan menambahkan cheese mousse dan honey bubble yang merupakan ciri khas dari HAN Dynastea. Cheese tea yang berhasil merebut perhatian masyarakat Indonesia ini sempat meramaikan pengguna media sosial.

Dengan strategi komunikasi yang dilakukan seperti melalui customer yang mempublikasi foto produk minuman HAN Dynastea dimedia sosial membantu dalam meningkatkan tingkat kesadaran serta minat beli akan produk dari HAN Dynastea. Ini juga merupakan sebuah kegiatan yang perlu untuk diulang guna memastikan produk dapat diterima oleh masyarakat dengan baik. Promosi dalam penjualan ini adalah kegiatan atau materi yang bertindak sebagai ajakan dan memberikan nilai tambah untuk konsumen dan kelompok franchise. Ada sebagian pihak yang melihat promosi sebagai pelengkap dari periklanan dan penjualan pribadi karena ini menyatukan keduanya, yang menjadikan masing-masing lebih efektif lewat penjualan. Meski demikian, dalam kenyataannya, promosi penjualan lebih dari sekedar pelengkap. 
Dengan demikian, tujuan penelitain ini adalah mengetahui strategi komunikasi pemasaran yang dilakukan oleh PT HAN INDOTAMA PERKASA dalam memperkenalkan brand minuman Han Dynastea. Hasil penelitian ini diharapkan menjadi bahan evaluasi kembali atas strategi promosi yang selama ini sudah dilakukan apakah sudah sesuai dengan harapan atau sebaliknya di PT. HAN INDOTAMA PERKASA dan membantu dalam memberikan saran dan solusi mengenai permasalahan yang sedang dihadapi PT. HAN INDOTAMA PERKASA.

Menurut Onong Uchjana Effendy dalam buku Dimensi-Dimensi Komunikasi Suryadi (2018:5) yaitu yang menyatakan "strategi komunikasi merupakan panduan dari kegiatan perencanaan komunikasi (communication planning) dan manajemen (communication management) untuk mencapai suatu tujuan. Maka untuk mencapai tujuan tersebut strategi komunikasi harus dapat menunjukkan bagaimana operasionalnya secara taktis harus dilakukan, dalam arti kata bahwa pendekatan (approach) bisa berbeda sewaktu-waktu yaitu tergantung dari situasi dan kondisi pula.

Komunikasi pemasaran dapat diartikan sebagai suatu kegiatan pemasaran dengan menggunakan teknik-teknik komunikasi yang bertujuan untuk memberikan informasi kepada khalayaknya agar tujuan sebuah perusahaan dapat tercapai, yaitu dengan terjadinya pendapatan atas penggunaan jasa dan pembelian produk yang akan ditawarkan (Kennedy dan Soemanagara, 2006). Menurut Morrisan (2010), komunikasi pemasaran terpadu merupakan upaya untuk menjadikan seluruh kegiatan pemasaran dan promosi perusahaan agar dapat menghasilkan citra atau image yang bersifat satu dan konsisten bagi konsumen. Upaya ini juga menuntut agar setiap pesan yang keluar harus berasal dari sumber yang sama sehingga segala informasi yang diumumkan dari perusahaan memiliki kesamaan tema serta positioning yang sama di mata konsumen.

Hasil penelitian Septian (2016) menunjukkan bahwamelalui kegiatan promosi penjualan dengan berbagai cara, yakni: menghadirkan menu-menu baru yang di inovasi dan bervariasi serta dengan tampilan yang unik dengan harga bersahabat. Tidak hanya itu memberikan potongan harga disaat hari besar seperti Ulang Tahun dan hari besar lainnya. Di khususkan untuk konsumen setia, maka diberikan reward dengan dapat memilih bisa mendapatkan diskon harga atau mau mendaptakan bonus.

Penelitian Indriani (2017) juga mengungkapkan bahwa kegiatan komunikasi pemasaran yang dilaksanakan secara total mampu menjadi strategi yang sangat penting dalam pembangunan sebuah merek. Untuk menjalankan sebuah strategi komunikasi pemasaran terpadu, sebuah perusahaan atau pelaku bisnis sebaiknya mempersiapkan terlebih dahulu apa yang akan dilakukan. Diperkuat dengan pendapat Setyanto dkk. (2017) bahwa kegiatan branding sering diidentikkan dengan keberadaan sebuah institusi bisnis yang berorientasi profit. Dalam upaya melakukan branding, humas sering mendukung upaya ini.

\section{Metode Penelitian}

Pendekatan penelitian ini menggunakan metode kualitatif karena untuk mendapatkan data yang mendalam dan mengandung makna, sehingga dapat mengungkapkan fakta nyata di lapangan. Jenis penelitian yang digunakan dalam penelitian ini adalah penelitian yang bersifat studi kasus karena strategi pokok pertanyaan suatu peneilitian berkenaan dengan how atau why. Lokasi penelitian ini adalah PT. HAN INDOTAMA PERKASA di Jl. Pluit Karang Cantik No.21, Pluit, Penjaringan, Jakarta Utara dengan periode waktu penelitian Bulan 2 Mei 2019 s/d 3 Juni 2019. Metode pengumpulan data dalam penelitian ini adalah wawancara dengan 
partisipan Chief Executive Officer, customer, dan karyawan store HAN Dynastea. Mereka dipilih karena mereka yang lebih mengetahui mengenai produk minuman dari HAN Dynastea itu sendiri. Selain itu, dilakukan observasi untuk memperkuat hasil wawancara. Teknik keabsahan data menggunakn triangulasi dan teknik analisis data menggunakan deskriptif kualitatif.

\section{Hasil Temuan dan Diskusi}

\section{Strategi Komunikasi Han Dynastea dalam Penjualan Produk}

Strategi komunikasi merupakan panduan dari kegiatan perencanaan komunikasi (communication planning) dan manajemen (communication management) untuk mencapai suatu tujuan. Maka untuk mencapai tujuan tersebut strategi komunikasi harus dapat menunjukkan bagaimana operasionalnya secara taktis harus dilakukan, dalam arti kata bahwa pendekatan (approach) bisa berbeda sewaktu-waktu yaitu tergantung dari situasi dan kondisi pula (Suryadi, 2018).

Menurut Kotler (2016) ada dua strategi yang sering digunakan perusahaan dalam mengelola saluran pemasaran terutama dalam penciptaan saluran pemasaran baru, yaitu strategi dorong (push strategy) dan strategi dorong (pull strategy). Pemakaian strategi ini tergantung keputusan perusahaan terutama tergantung pada popularitas produk perusahaan tersebut. Strategi dorong (push strategy) dalam pelaksanaannya adalah mencoba membujuk perantara agar mau memasarkan produknya dengan memberikan fasilitas-fasilitas tertentu, misal potongan yang tinggi dalam pembelian produk. Strategi ini cocok dilakukan untuk produk yang loyalitas mereknya masih rendah dan pilihan merek dilakukan ditoko. Strategi ini cocok untuk produk baru yang mempunyai dana promosi terbatas, sehingga mencoba menggunakan saluran pemasaran yang sudah berpengalaman dalam memasarkan berbagai produk.

Strategi tarik (pull strategy) dalam pelaksanaannya dengan cara perusahaan membangun positioning produk melalui promosi ke konsumen seperti iklan media cetak, elektronik atau melalui even-even. Sehingga dengan fokus kepada promosi akan membuat konsumen tertarik untuk mencoba.

Dapat dipahami bahwa adanya strategi komunikasi yang dilakukan Han Dynastea dalam memperkenalkan brand nya dengan kegiatan seperti push and pull. Seperti kita ketahui strategi tersebut merupakan tujuan dari mencipatakan usaha komunikasi yang baik. Ini bertujuan untuk memperkenalkan brand minuman dari Han Dyanstea dan juga untuk lebih menarik perhatian dari calon pembeli. Dalam setiap usaha perkembangan yang mengarah lebih maju tentu membutuhkan perhatian dari calon pembelinya dengan tujuan untuk mendapat timbal balik yang memberikan keuntungan. Maka setiap perusahaan memerlukan dan menyiapkan strategi-strategi yang mengarah pada peningkatan penjualan dan pemasukan untuk peusahaannya. Ini juga untuk menciptakan komunikasi yang dibutuhkan agar mendapat respon yang baik pula dari para customer. Dimana kegiatan ini juga adalah strategi komunikasi yang tentu direncanakan agar mencapai tujuan tertentu suatu perusahaan.

Berikut penjelasan hasil wawancara dari CEO (Chief Executive Officer) Han Dynastea yaitu Daniel Dewata,

"Oke, prinsip dari strategi yang kami gunakan adalah push and pull harus seimbang, yang mana push ketika kami melakukan iklan, endorse, dan bentuk promosi lainnya baik offline maupun online dan pull strategy nya kami terapkan melalui letak store yang dapat dijangkau konsumen dengan mudah. 
Sehingga terjadi kesinambungan antara ketertarikan yang diciptakan di pasar dan juga supply atau keterjangkauan produk yang mudah."

\section{Komunikasi Pemasaran Membangun Image yang Baik}

Pengertian tentang komunikasi pemasaran terpadu merupakan upaya untuk menjadikan seluruh kegiatan pemasaran dan promosi perusahaan agar dapat menghasilkan citra atau image yang bersifat satu dan konsisten bagi konsumen (Morrisan, 2010:9). Definisi lain juga tentang komunikasi pemasaran dapat diartikan sebagai suatu kegiatan pemasaran dengan menggunakan teknik-teknik komunikasi yang bertujuan untuk memberikan informasi kepada khalayaknya agar tujuan sebuah perusahaan dapat tercapai, yaitu dengan terjadinya pendapatan atas penggunaan jasa dan pembelian produk yang akan ditawarkan (Kennedy dan Soemanagara, 2006:5)

Han Dynastea dalam membangun citra atau image yang baik melalui kegiatan komunikasi pemasaran yaitu dilakukan oleh karyawannya adalah seperti mengutamakan sikap yang ramah dalam melayani pembeli dengan tujuan membangun hubungan baik agar menciptakan rasa nyaman. Kemudian juga menawarkan menu yang disediakan oleh Han Dynastea untuk lebih mengetahui varian dari produk. Lalu dengan memberikan kartu member khusus selain untuk mengetahui apakah pembeli akan datang lagi untuk membeli produk serta mengetahui kepuasan dari pembeli terhadap produk Han Dynastea. Ini juga memungkinkan pelanggan lebih setia dan senang karena dengan adanya member tersebut menyediakan berbagai macam reward yang diberikan oleh Han Dynastea.

Komunikasi pemasaran yang dilakukan Han Dynastea adalah melalui karyawannya yaitu seperti selalu berusaha dalam menunjukkan sifat ramah yang bertujuan membangun sebuah komunikasi dan hubungan yang baik, mempromosikan brand minumannya melalui menawarkan varian produk minuman dari menu yang disediakan, berusaha untuk melakukan pelayanan yang baik kepada pembeli guna menciptakan kesan yang baik pula sehingga dapat membentuk citra atau image yang baik bagi perusahaannya.

\section{Penerapan Komunikasi Pemasaran Bauran di PT. HAN INDOTAMA PERKASA dalam Membangun Brand Han Dynastea}

Perusahaan-perusahaan itu mulai bergerak menuju sebuah proses yang disebut dengan komunikasi pemasaran terpadu atau integrated marketing communication (IMC), yang mencakup bahwa setiap upaya koordinasi dari berbagai elemen promosi dan pemasaran lainnya tersebut dengan bauran komunikasi pemasaran yang terdiri atas beberapa bagian berikut. (Priansa, 2017).

Ada beberapa kegiatan komunikasi pemasaran bauran yang dilakukan Han Dynastea untuk mencapai tujuannya yaitu berusaha untuk membangun dan memperkenalkan brand produk minumannya. Internet menjadi salah satu peran penting membantu kerja orang lebih cepat, mudah dan dapat menjangkau. Dari internet kemudian kita mengenal kegiatan publikasi yang sering digunakan melalui sosial media. Sosial media yang tidak lagi asing didengar hampir pada semua kalangan menggunakannya. Dalam kegiatan komunikasi pemasaran pada Han Dynastea tidak terlepas dari publikasi melalui sosial media yang berperan besar. 


\section{a. Periklanan (advertising)}

Kegiatan untuk memperkenalkan brand dari Han Dynastea tidak terlepas dari iklan-iklan melalui sosial media misalnya melalui Instagram (han.dynastea) seperti menampilkan foto dari menu varian produk minumannya, adanya informasi-informasi seperti promo apa saja yang dihadirkan, memberikan informasi mengenai lokasi store, juga menginfokan aplikasi-aplikasi apa saja yang digunakan untuk mempermudah pemesanan.

\section{b. Pemasaran langsung (direct marketing)}

Pada Han Dynastea pemasaran langsung tersebut dilakukan seperti melalui insta ads (aplikasi fitur dari Instagram yang dapat menjangkau market atau customer baru), brosur (informasi yang disebarkan serta penawaran tentang produk), iklan promo dari aplikasi gojek (adanya gambar promo yang menarik dari produk yang bertujuan untuk memasarkan Han Dynastea serta menarik pembeli), ketika hadirnya menu baru dari Han Dynastea (memberi free tester produk menu baru kepada customer kemudian meminta feedback). Pemasaran ini dilakukan tentu bertujuan untuk memasarkan produk kepada marketnya.

\section{c. Promosi penjualan (sales promotion)}

Han Dynastea juga tidak terlepas dari kegiatan berbagai macam promosi. Promosi tersebut seperti memberi diskon pada harga produk seperti buy one get one free, promo buy two get three, promosi melalui undian berhadiah emas antam dua gram, even-even tertentu seperti hari valentine Han Dynestea membagikan bunga dan free produk minuman Han Dynastea dan juga menggunakan banner sebagai promosi offline dalam memberikan informasi promo pada produk minumannya. Sehingga kegiatan promosi ini yang diharapkan agar produk dari brand Han Dynastea dapat menarik calon pembelinya dan bertujuan juga untuk meningkatkan nilai jual.

d. Penjualan personal (personal selling)

Penjualan Personal (Personal Selling) yang dilakukan Han Dynastea ketika mengikuti event-event tertentu. Seperti bazaar Explore Rasa (Summarecon Mall Serpong), Alumni Home Coming (Prasetya Mulia University), I Love Bazaar Pop Up Market (Kuningan City Mall) dan lain sebagainya.

\section{e. Pemasaran interaktif (interactive marketing)}

Pemasaran Interaktif (interactive marketing) dalam Han Dynastea yaitu memilih internet kemudian melalui sosial media sebagai jalurnya dalam memperkenalkan dan memberi informasi tentang apa saja yang ditawarkan dari Han Dynastea. Pemasarannya seperti melalui Instagram, go food, grab food, media massa elektronik. Pemasaran interaktif ini juga dipilih oleh Han Dynastea karena sangat berperan penting dalam upaya memperkenalkan brand minumannya melalui beberapa aplikasi yang aktif pada saat ini atau juga melalui media-media yang dapat meliput.

\section{Merek dari Brand Minuman Han Dynastea}

Kotler berpendapat dalam buku Sadat (2009) bahwa "sebuah merek adalah sebuah nama, istilah, tanda, simbol, atau desain atau kombinasi dari semuanya, dimaksudkan untuk mengenali barang atau jasa untuk penjual perseorangan atau kelompok dan untuk membedakan mereka dari kompetitornya."

Definisi mengenai merek juga dijelaskan Tjiptono dan Diana (2018) bahwa merek adalah nama, istilah, simbol, atau desain, maupun kombinasi di antaranya yang dimaksudkan untuk mengidentifikasi barang atau jasa para pesaing. 
Han Dynastea menggunakan sebuah logo unik yang bertujuan untuk dijadikan tanda pengenal dari brand mereka. Logo ini juga digunakan sebagai identitas brand minuman Han Dynastea. Han Dynastea memilih logo visual, sedangkan gambar pada logo nya sendiri yaitu Han yang dijadikan mascot seorang anak muda yang bersifat ceria dan hidup di dalam kerajaan yang memiliki sumber daya teh sangat baik lalu, juga kerajaan tersebut terkenal dengan keahliannya dalam meracik produk teh. Sehingga dengan logo Han tersebut menjadi salah satu poin penting sebagai suatu daya tarik pembeli. Menjadi daya tarik yang menonjol dari brand Han Dynastea karena memiliki logo yang cukup menarik perhatian pembeli. Lalu ini tentu bertujuan untuk lebih mudah diingat melalui logo Han Dynastea yang menarik yaitu dengan tampilan yang cukup lucu dan unik. Maka dari itu logo sangat penting untuk menyadarkan serta mudah diingatnya sebuah produk dari suatu brand dibandingkan hanya sekedar tulisan saja. Ini juga menjadi identitas produk dari brand Han Dynastea.

\section{Brand Awareness pada Han Dynastea}

Kesadaran merek menurut Hasan (2013) adalah menyatakan tentang tingkat kesadaran seseorang untuk mengenal atau mengetahui adanya sebuah merek sebagai bagian dari kategori produk terebut. Kesadaran (awareness) juga upaya untuk bagaimana konsumen merasa familiar misalnya dengan melalui sebuah iklan, promosi penjualan produk atau jasa, dan juga menggunakan komunikasi pemasaran lainnya mengenai sebuah merek, yang kemudian memberikan informasi kepada orang-orang tentang ciri khusus yang dimiliki serta manfaatnya, adanya kegiatan dalam menunjukan perbedaannya dari merek pesaing, lalu menginformasikan bahwa merek yang akan ditawarkan lebih baik ditinjau dari sisi fungsional dan simbolisnya. (Shimp, 2003).

Han Dynastea memilih sebuah merek nama dan gambar logo yang menjadi identitasnya melalui sebuah desain yang menarik. Mengingat adanya sebuah merek dan logo akan berperan besar dalam daya tarik tersendiri bagi pembeli. Dengan demikian memiliki merek dan logo yang unik dapat mempermudah pembeli untuk lebih sadar dan mengingat akan produk minuman dari brand Han Dynastea.

Dengan berkembangnya brand Han Dynastea seperti memiliki cabang di dalam kota maupun luar kota yaitu Tangerang, Jakarta Utara, Bandung, Surabaya dan Makassar melalui franchise ini selain meningkatnya nilai jual dari produk namun dengan franchise produk yang ditawarkan lebih mudah untuk dijalankan. Karena melalui franchise juga membantu dalam tingkat brand awareness akan suatu brand seperti lokasi store nya yang tersebar di beberapa tempat. Dengan demikian, ketika konsumen memiliki tingkat kesadaran akan suatu brand maka dapat mempermudah dalam menawarkan produknya kepada target pasar yang dituju. Dengan demikian

brand produk minuman dari Han Dynastea secara mudah dapat diketahui keberadaannya oleh customer nya, dapat meningkatkan pendapatan keuntungan melalui brand awareness yang tinggi dan juga memperkuat brand nya melalui franchise atau memiliki cabang store.

\section{Simpulan}

Dalam kegiatan penjualan produk minumannya Han Dynastea menggunakan strategi push and pull dalam memperkenalkan brand minuman Han Dynastea. Untuk membangun suatu image yang baik Han Dynastea melakukan suatu kegiatan melalui 
komunikasi pemasaran seperti memberi pelayanan yang baik kepada customer, menawarkan menu dari varian produk minuman Han Dynastea, dan memberikan reward melalui member khusus pada pelanggan. Han Dynastea juga menggunakan logo yang khas dan menarik sebagai tanda pengenal dari merek brand minumannya. Brand awareness pada Han Dynastea yaitu seperti memilih merek, logo, iklan-iklan dan promosi-promosi mengenai brand minumannya. Pemanfaatan sosial media untuk memperkenalkan dan memperkuat brand Han Dynastea di masyarakat..

\section{Ucapan Terima Kasih}

Ditulis dengan font Times New Roman 12 poin, spasi 1. Ucapan terima kasih berisi mengenai pihak-pihak yang secara langsung memberikan kontribusi dalam penelitian ini, seperti narasumber, pemberi dana, pembimbing, dll. Maksimum penulisan ucapan terima kasih adalah 50 kata.

\section{Daftar Pustaka}

Hasan, A. (2013). Marketing dan Kasus-Kasus Pilihan. Yogyakarta : CAPS (Center for Academic Publishing Service).

https://m.detik.com/food/info-kuliner/d-3895304/gimana-ya-rasa-teh-melati-dancokelat-kalau-dilapisi-creamcheese?ga=2.35246497.1411258736.1552458042-1411790695.1552458042

Indriani, E. (2017). Strategi Komuikasi Pemasaran Terpadu Untuk Meningkatkan Ekuitas Merek Selopos. http://eprints.ums.ac.id/54111/3/Naskah\%20publikasi\%20el.pdf

Kennedy, J. E. dan Soemanagara, R. D. (2006). Marketing Communication - Taktik dan Strategi. Jakarta : PT. Buana Ilmu Populer.

Kotler,P. \& Keller,K. L. (2016). Marketing management. 15th, Boston : Pearson Education

Morissan. (2010). Periklanan. Jakarta : Prenadamedia Group

Priansa. (2017). Komunikasi Pemasaran Terpadu. Bandung : CV Pustaka Setia

Sadat, A. M. (2009). Brand Belief : Strategi Membangun Merek Berbasis Keyakinan. Jakarta : Salemba Empat.

Septian, D. (2017). Strategi Komunikasi Pemasaran Café Tong Susu Pekanbaru Dalam Meningkatkan Jumlah Konsumen. https://media.neliti.com/media/publications/33066-ID-strategi-komunikasipemasaran-cafe-tong-susu-pekanbaru-dalam-meningkatkan-jumlah.pdf

Setyanto, Y. Anggarina, P. T. \& Valentina, A. (2017). Branding yang Dilakukan Humas Pada Perguruan Tinggi Swasta. http://ejournal.adbisnis.fisipunmul.ac.id/site/wp-

content/uploads/2016/11/01_format_artikel_ejournal_mulai_hlm_ganjil\%20(11 $-16-16-05-50-26) \cdot p d f$

Shimp, A. T. (2003). Periklanan Promosi : Komunikasi Pemasaran Terpadu. Jakarta : Erlangga.

Suryadi, E. (2018). Strategi Komunikasi. Bandung : PT Remaja Rosdakarya.

Tjiptono, F. dan Diana, A. (2018). Pemasaran. Yogyakarta : C.V Andi Offset. 